\title{
Investigation of Peanut Shell as Alternative Sound Absorbing Material
}

\author{
Ulhas Arun Malawade, Madhavrao Ganpatrao Jadhav \\ Department of Mechanical Engineering, Savitribai Phule Pune University, Pune, India
}

Email address:

meetulhas@gmail.com (U. A. Malawade)

\section{To cite this article:}

Ulhas Arun Malawade, Madhavrao Ganpatrao Jadhav. Investigation of Peanut Shell as Alternative Sound Absorbing Material. American Journal of Mechanical and Materials Engineering. Vol. 3, No. 3, 2019, pp. 53-60. doi: 10.11648/j.ajmme.20190303.12

Received: July 16, 2019; Accepted: August 23, 2019; Published: September 5, 2019

\begin{abstract}
Use of natural material for development of sound absorbers received considerable significance since in past few years. Natural materials are preferred due to their ease of availability, low environmental impact, distinctive internal structure and reusability. One such natural material Peanut shell is made up of natural cellulose fibers and has good internal pores which can be utilized for sound absorption application. In the current study samples of Peanut shell specimens were made of $100 \mathrm{~mm}$ diameter having different material to binder weight ratios. The test specimens were made with thickness $10 \mathrm{~mm}, 15 \mathrm{~mm}, 20 \mathrm{~mm}$, $25 \mathrm{~mm}, 30 \mathrm{~mm}, 35 \mathrm{~mm}$ and $40 \mathrm{~mm}$ respectively. Normal incidence sound absorption coefficient for the specimens is measured using ASTM E1050-98 (Standard Test Method for Impedance and Absorption of Acoustical Materials Using a Tube, Two Microphones, and a Digital Frequency Analysis System) and values of the normal incidence sound absorption are compared with values obtained using Delany and Bazley Model. It was observed that Peanut shell test specimen with material to binder weight ratio 70:30 gives optimum average sound absorption for frequency range between $250 \mathrm{~Hz}$ to $4500 \mathrm{~Hz}$. The current paper concludes that Peanut shell can prove to be good alternative natural material over existing conventional sound absorbing materials for application in field of sound absorption.
\end{abstract}

Keywords: Acoustics, Impedance Tube, Noise, Peanut Shell, Sound Absorption Coefficient, Natural Fibers

\section{Introduction}

Need for creating more comfortable environment in specific areas like schools, offices, hospitals, industries, malls, theaters and study centers is mandatory. Many engineering and architectural techniques are adopted to solve the noise related problems to environmental conditions at such places. Noise is the greatest concern which is required to be controlled at minimal expenses. At present synthetic sound absorbing materials like glass wool, rock wool, shoddy and polyurethane foams are used for controlling the noise level at these places. Use of synthetic materials has its limitations as they are expensive, non-degradable and non- recyclable. These limitations lead to conduct more research for alternative solution on the synthetic materials.

\section{Literature Survey}

Hasina Mamtaz et al. [1] developed natural sound absorber from the composition of fibrous and granular materials. Their effort in manufacturing of composite sound absorbing materials with coconut coir fiber and rice husk had additional benefits like cost effective and efficient performance. The sound absorption coefficient is measured by using a set of two impedance tube as per ASTM E1050-98 standard. And the results obtained were compared with the existing synthetic materials especially at low frequencies. Zhengqing Lou et al. [2] in their work on multilayer sound absorbers having various layers of 3D printed micro perforated polymeric panel and non-woven recycled cotton backing gave them efficient way of obtaining better results at higher frequency sound absorption. C. Arenas et al. [3] in their efforts on use of alternate methodology for measurement of sound absorption of composite materials manufactured using coal bottom ash formed by pulverized coal combustion. Acoustic behavior for materials with different thickness and multilayer composite products is predicted using the intrinsic properties like porosity and static airflow resistivity which were found using impedance tube. Results from the simulation software SIMAM and CARAM were compared with the values 
obtained using the reverberation room method.

A. Farhad Forouharmajd et al. [4] in their efforts in investigation of normal incidence sound absorbing capacity of materials manufactured from polyurethane foam, polystyrene, polyvinylchloride (PVC), rubber, mineral wool carpet and glass samples. Wherein the specimen thickness $25 \mathrm{~mm}$ is kept constant for all the test samples and it is found that mineral wool gives sound absorption of about 0.97 at frequency range between 500 $\mathrm{Hz}$ to $4500 \mathrm{~Hz}$. Khai Hee Or et.al [5] believed that the oil palm empty fruit bunch fiber could prove to be sustainable option as alternative sound absorbing materials. They obtained the fibers by mechanical retting process and further prepared the samples having diameter $33 \mathrm{~mm}$ and different thickness. Samples are prepared by compression of fibers in aluminum mold at $100^{\circ} \mathrm{C}$ for 5 minutes. Test for sound absorption is performed on impedance tube using ISO 10534-2 standard for determination of sound absorption coefficient and impedance in impedance tubes by varying density, air gap and thickness of samples. It was observed that the absorption coefficient improves with increase in air gap and increase in density till a certain point beyond which later sound absorption decreases. B. Botterman et al. [6] discussed modeling and optimization of wood wool cemented boards to deliver more effective model for obtaining better accuracy in predicting sound absorption coefficients for wood wool cemented boards. They had compared three impedance model namely Attenborough model, Johnson- ChampoxAllard (JCA) model and Johnson- Champox- AllardLafarge (JCAL) Model. The authors reported that JCA model gives better results as compared to other model as it takes five parameter into consideration namely porosity, flow resistivity, tortuosity, viscous and thermal characteristic lengths that largely influence the sound absorption. Manthan Sambu et al. [7] prepared sound absorber from non-woven aregna pinnata (ijuk) fiber and natural rubber. While making samples the ijuk was firstly soaked in alkaline then mixed with natural rubber later on heating and compression was performed. Paper reports samples made with combinations of 80:20, 70:30, 60:40 of above combination with a $50 \mathrm{~mm}$ fixed thickness and diameter of $100 \mathrm{~mm}$. It was observed that use of natural rubber as binder improves the sound absorption coefficient. For frequency of $100 \mathrm{~Hz}$ Sound absorption average (SAA) was 0.9 for 80:20 composition which was found to be optimum. Hasina Mamtaz et al. [8] mentions the drawbacks of use of natural fiber without support of synthetic fibers. Paper reports composite sound absorbing materials made up of fibro granular material mixed with natural rubber and polymer fiber matrix. As the rubber granules have high porosity which further improves tortuosity and flow resistivity. It is observed that decrease in rubber grain size improves the sound absorption whereas alkaline treatment gives good low frequency sound absorption and increase in the air flow resistivity with improvement in overall performance. Ancuta-Elena
Tiuc et al. [9] introduced the use of textile waste for improving the sound absorption for polyurethane foam. Isocyantel polyol mixture gives polyurethane foam with blow agent as catalyst forms to produce rigid composite matrix with textile waste. It is observed that combination of $75 \%$ rigid polyurethane foam (RPF) and 25\% textile waste gives SAA of 0.86 at $1000 \mathrm{~Hz}$ which is seen as better among other combinations. Cinzia Burtti et al. [10] used recycled materials for building applicationsto achieve low cost production of panels. Paper reports use of recycled paper and other scrap materials as wool and nonwoven polyester fabric due to their good acoustic behavior. Samples with diameter of $29 \mathrm{~mm}$ and $100 \mathrm{~mm}$ were manufactured with different thickness. These samples were tested on two microphone impedance tube of standard ISO 10534-2. Both types of panels were applied on ceilings of lecture hall. It was observed that performance of recycled material panels meets the performance of conventional material panels. Daniela Bosnia et. al [11] had used recycled sheep wool as sound absorbing material as it has advantages like biodegradable and easy available. Test panels were made with area of 12 $\mathrm{m}^{2}$ and $50 \mathrm{~mm}$ thickness and $130 \mathrm{~kg} \cdot \mathrm{m}^{-3}$ density. Specimens were tested for frequency range between $100 \mathrm{~Hz}$ to $500 \mathrm{~Hz}$. It was found that sheep wool gives good absorption at low as well as high frequencies as compared to glass and rock wool having similar density. M. T. Fadzlita et al. [12] made use of coir fiber material panels for application in sound absorption. Objective of work was to study the effect of varying percentage of perforated zinc plates covering the coir fiber panel in order to improve the acoustic performance. The perforated sheet with $6.92 \%$ and $19.23 \%$ perforation percentages were used with the panels. It was found the high perforation percentages increase the sound absorption. The peak value like 0.73 was achieved at frequency of $2000 \mathrm{~Hz}$. A. K. Elwaleed et al. [13] had approach for utilization of date palm fiber as sound absorbing material. Average diameter of fiber is around $0.408 \mathrm{~mm}$ with density of $919 \mathrm{Kg} . \mathrm{m}^{-3}$ respectively. Mold with two different diameter and range of sizes were used to prepare samples. Uncompressed sample size $30 \mathrm{~mm}$ is compressed to a thickness of $23 \mathrm{~mm}$ with compression ratio of 1.3 , it was observed that the value of absorption coefficient increase with increase in flow resistivity. As the compression rate is increased to 2.3 the performance of the sample decreases. Tucheng Hung et al. [14] efforts on the use of blast furnace slag of calcium oxide and silicon dioxide for manufacturing of inorganic polymeric foam (IPF). Paper repots use of inorganic polymeric foam as sound absorbing materials. Foams were manufactured with densities $0.4,0.6,0.8$ and $1.0 \mathrm{~g} . \mathrm{cm}^{-3}$ and were cut in size of $4 \mathrm{~cm}$ and $6 \mathrm{~cm}$ thickness respectively. It was observed that sound absorption increases as the density of specimen decreases from $1.0 \mathrm{~g} . \mathrm{cm}^{-3}$ to $0.4 \mathrm{~g} . \mathrm{cm}^{-3}$ regardless to frequency. Hai-fan Xianga et al. [15] suggested the use of kapok fiber for noise reduction applications. They had investigated 
acoustical properties of the kapok fiber by use of modified Delany and Bazley model and normal absorption coefficient were found using the SW 466 Impedance tube (transfer function method). It was observed kapok fibers have good acoustical damping properties due to its hollow structure and hence can be used in noise reduction. Lamyaa Abd Al Rahman et al. [16] conducted study on the natural fiber for green acoustic absorbing materials. The two micro porous materials namely Date Palm Fiber (DPF) and Coconut Coir Fiber (CCF) are considered for the study. Samples with thickness range $10 \mathrm{~mm}-40 \mathrm{~mm}$ and density variation between 90-160 kg.m ${ }^{-3}$ were manufactured. Acoustical absorption coefficient values of DPF and CCF were compared with each other. It was observed that increase in the bulk density of natural fiber gives better performance in sound absorption. Sezgin Ersoy et al. [17] investigated the sound absorbing properties of industrial tea leaf fiber waste which is hygienic and ecofriendly in nature and can prove to be good alternative for manufacturing of acoustic absorbing materials. Samples form Woven Cotton Cloth (WCC), Propylene based nonwoven fiber (PNF) and Tea Leaf Fiber (TLF) were manufactured with thickness range of $10 \mathrm{~mm}, 20 \mathrm{~mm}$, and $30 \mathrm{~mm}$. Results were compared with each other and it was observed that TLF of $30 \mathrm{~mm}$ sample size gives SAA 0.75 for frequency range between $500-3500 \mathrm{~Hz}$.

It can be seen that there is extensive scope for use of natural materials for utilizing acoustic materials. Natural materials are preferred due to their ease of availability, low environmental impact, distinctive internal structure and reusability; they can prove to be good alternative over existing synthetic materials. Objective of this work is to investigate the sound absorbing potential of peanut shell waste (a natural material).

\section{Test Specimen Preparation}

Peanut also known as ground nut is a legume crop grown mainly for its edible seeds and cultivated in tropical or subtropical regions. Global annual production of shelled peanuts was 42 million tonnes in 2014 from which 6.6 million tonnes was produced in India. Large production generates large waste in the form of peanut shell. Peanut shell waste is commonly used in modern stock husbandry, biomass for house hold use or making of byproducts. Besides this peanut shell have low density, low thermal conductivity and porosity. To make the samples from the peanut shells, steel molds were prepared with internal diameter of $100 \mathrm{~mm}$ with different thickness viz. $10 \mathrm{~mm}, 15 \mathrm{~mm}, 20 \mathrm{~mm}, 25 \mathrm{~mm}, 30 \mathrm{~mm}, 35 \mathrm{~mm}$ and $40 \mathrm{~mm}$ respectively. Steel mold were cut by using gas cutting machine as shown. Figure 1 shows the test Specimen of molds prepared with $100 \mathrm{~mm}$ diameter of various thickness.

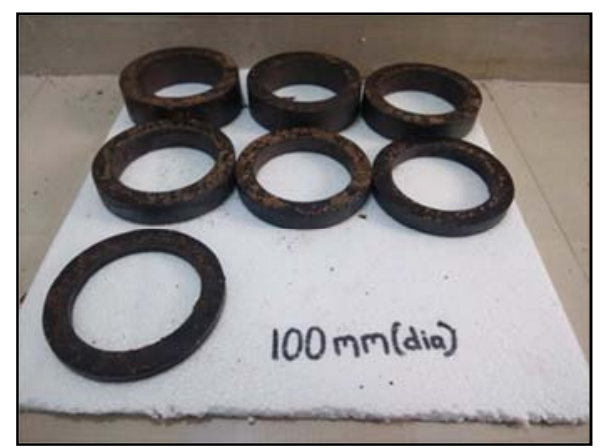

Figure 1. Test Specimen Molds of $100 \mathrm{~mm}$ diameter with various thickness range.

Figure 2 shows the flow chart of steps used for test specimen preparation from collection of peanut shell till sample preparation.

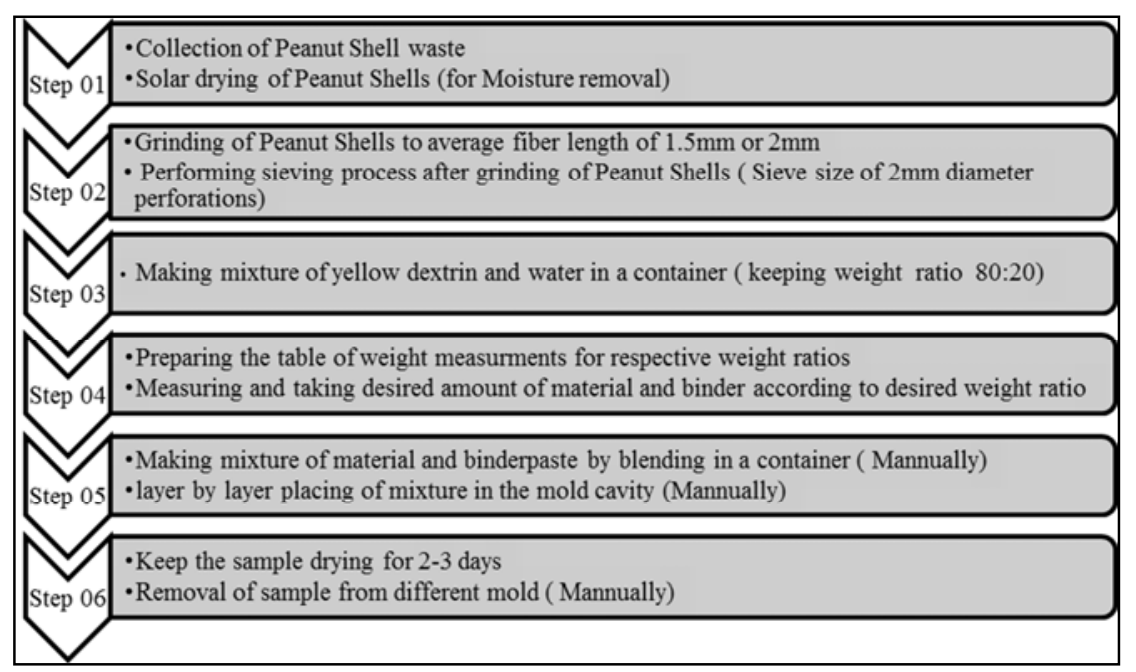

Figure 2. Steps for test specimen preparation process flow chart.

Molds are made in different thickness range with constant internal diameter of $100 \mathrm{~mm}$ and outer diameter of $135 \mathrm{~mm}$ respectively as shown in Figure 1. The sample preparation process has been briefed in the flow chart as shown in Figure 2. The process includes the use of blender, sieving equipment's and clamps, plates, containers, brushes etc. Adhesive used in the sample preparation is yellow dextrin which is made of corn starch. It is referred to be natural binder for use in sample preparation. Yellow dextrin is available in the form of powder as industrial adhesive as shown in Figure 3. 


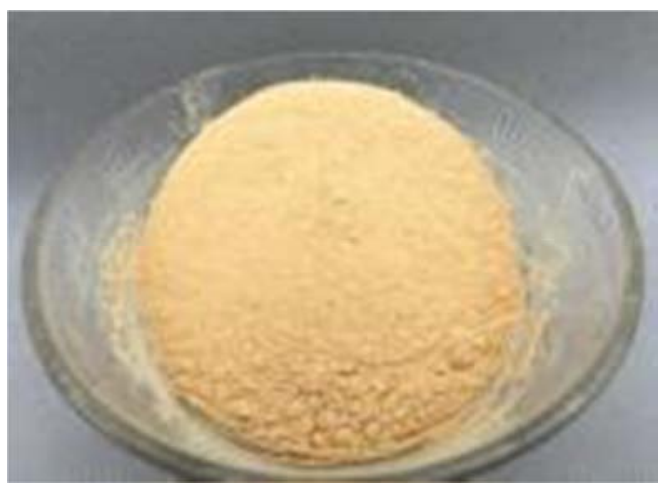

Figure 3. Yellow dextrin powder.

Measurements of the material and binder were taken using electronic weight measuring machine having capacity to accurately measure from 1 gram. Samples made with different material to binder weight ratios (MBWR) 55:45, 60:40, 65:35, 70:30 and 75:25 as shown in Figure 4 to Figure 8.

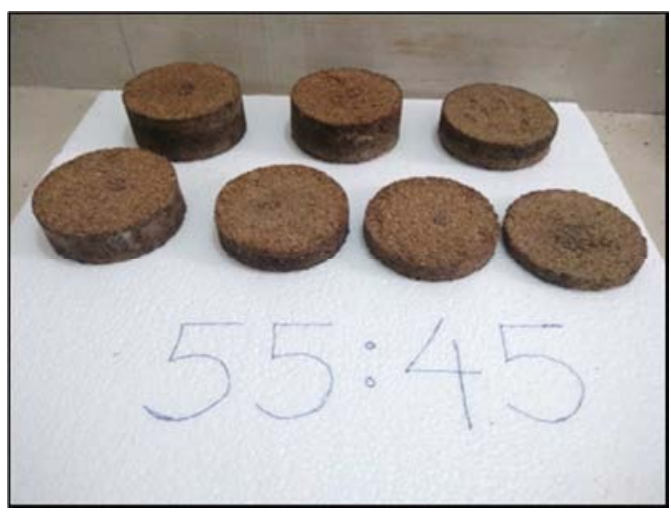

Figure 4. Test Specimen with material to binder weight ratio (MBWR) 55.45 .

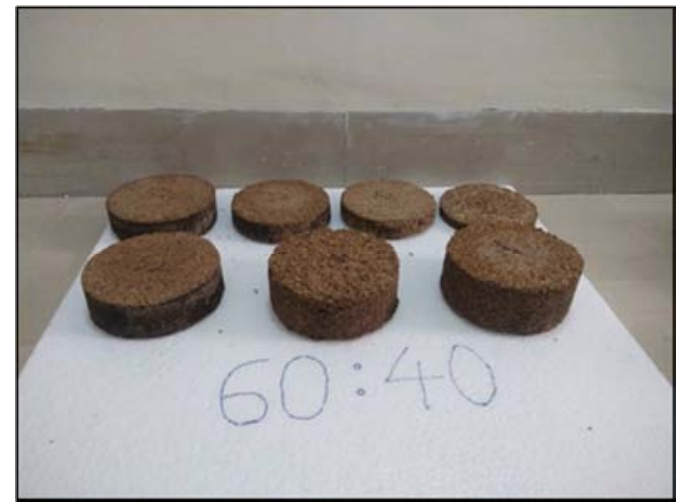

Figure 5. Test Specimen with MBWR 60.40 .

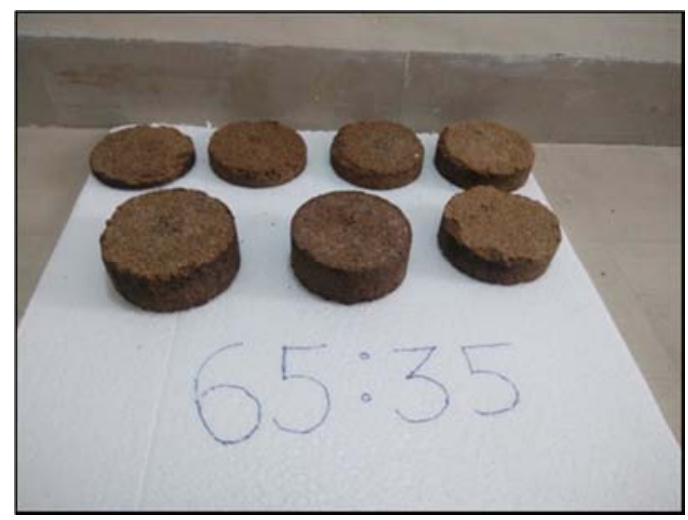

Figure 6. Test Specimen with MBWR 65.35.

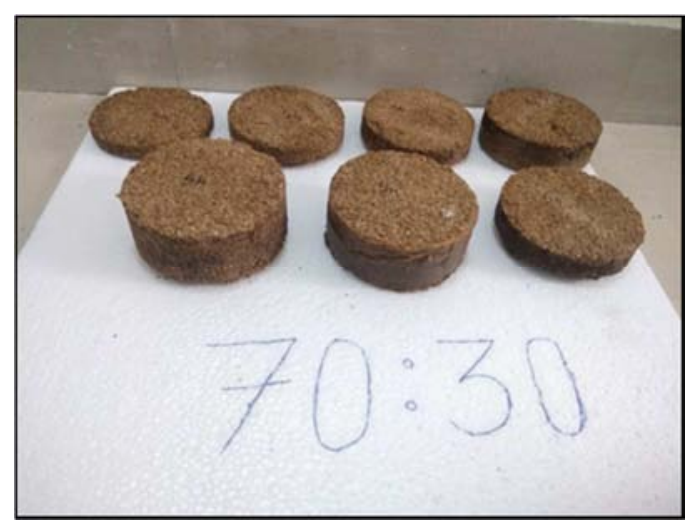

Figure 7. Test Specimen with MBWR 70.30.

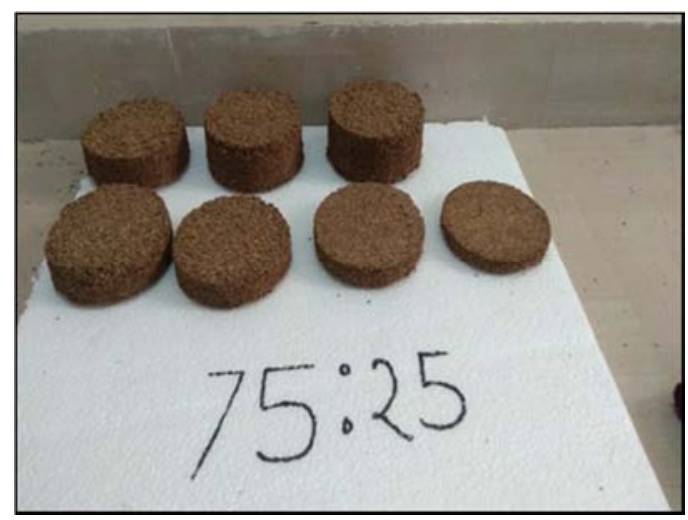

Figure 8. Test Specimen with MBWR 75.25.

These samples with different weight ratios have different bulk density for their respective thickness as shown in the Table 1.

Table 1. Bulk Densities values for test different Samples.

\begin{tabular}{|c|c|c|c|c|c|c|}
\hline Weight Ratios & & C1 (55:45) & C2 (60:40) & C3 (65:35) & C4 (70:30) & C5 (75:25) \\
\hline Thickness in $\mathrm{mm}$ & Volume in $\mathrm{mm}^{3}$ & Density in $\mathrm{kg} / \mathrm{m}^{3}$ & Density in $\mathrm{kg} / \mathrm{m}^{3}$ & Density in $\mathrm{kg} / \mathrm{m}^{3}$ & Density in $\mathrm{kg} / \mathrm{m}^{3}$ & Density in $\mathrm{kg} / \mathrm{m}^{3}$ \\
\hline 10 & 78539.81 & 611.2 & 636.6 & 585.7 & 611.2 & 471.1 \\
\hline 15 & 117809.7 & 645.1 & 611.2 & 628.1 & 628.1 & 619.6 \\
\hline 20 & 157079.6 & 604.8 & 541.1 & 547.5 & 598.4 & 515.7 \\
\hline 25 & 196349.5 & 646.8 & 621.3 & 519.5 & 728.3 & 601 \\
\hline 30 & 235619.5 & 619.6 & 636.6 & 539 & 679.1 & 700.3 \\
\hline 35 & 274889.4 & 669.4 & 844 & 516.6 & 753 & 734.8 \\
\hline
\end{tabular}




\section{Measurement of Sound Absorption Using Delany Bazley Model}

Mathematical model applied for estimating the normal sound absorption values generally depends upon distinctive absorption mechanism and category of porosity of the material been evaluated. Delany and Bazley model (DB Model) is most widely used for predicting the normal sound absorption values especially for natural fibers and porous sound absorbing materials. It is a simple model and requires non acoustical parameter of air flow resistivity for predicting the sound absorption values. It considers the porous layers as bulk materials including the rigid frame media of sample. Air flow resistivity is sufficient to define the characteristic wave impedance $\left(z_{c}\right)$ and propagation constant $\left(k_{c}\right)$ also known as complex wave number, the model for finding the values of sound absorption $(\alpha)$ is given below:

Air Flow resistance of sample $(R)$

$$
R=\frac{\Delta p}{Q}
$$

Specific air flow resistance $\left(R_{S}\right)$

$$
R_{s}=\frac{R}{A}
$$

Air Flow resistivity of material $(\sigma)$

$$
\begin{gathered}
\sigma=\frac{R_{s}}{d} \\
z_{c}=\rho_{0} c\left[1+0.078\left(\rho_{0} f / \sigma\right)^{-0.623}\right]-j 0.074\left(\rho_{0} f / \sigma\right)^{-0.66} \\
k_{c}=\omega / c\left[1+0.0987\left(\rho_{0} f / \sigma\right)^{-0.70}-j 0.189\left(\rho_{0} f / \sigma\right)^{-0.595}\right] \\
z_{s}=-j z_{c} \operatorname{Cot}\left(k_{c} d\right)
\end{gathered}
$$

$$
\begin{gathered}
r=\left(z_{s}-\rho_{0} c\right) /\left(z_{s}+\rho_{0} c\right) \\
\alpha=1-|r|^{2}
\end{gathered}
$$

Where,

$\rho_{o}=$ density of air $\left(\mathrm{Kg} . \mathrm{m}^{-3}\right)$

$c=$ Speed of sound at ambient conditions $\left(\mathrm{m} \cdot \mathrm{s}^{-1}\right)$

$Q=$ Air flow rate $\left(\mathrm{m}^{3} \cdot \mathrm{s}^{-1}\right)$

$A=$ Area of sample specimen $\left(\mathrm{m}^{2}\right)$

$\Delta P=$ Differential pressure $\left(\right.$ Pa.s.m $\left.{ }^{-1}\right)$

$f=$ Frequency $(\mathrm{Hz})$

$\omega=$ Angular Frequency (rpm)

$\sigma=$ Static air flow resistivity $\left(\right.$ Pa.s.m $\left.{ }^{-2}\right)$

$d=$ Thickness of sample $(\mathrm{m})$

$r=$ Sound pressure reflection coefficient

$\alpha=$ Sound absorption coefficient

\section{Measurement of Sound Absorption Using Impedance Tube Test Setup}

Impedance tube method (ASTM E1050-98) has more advantage when compared to other method because of its compact, low cost and speedy result generation features. In this method sound is created inside the impedance tube and made to incident on the acoustic material. From the reflected waves some of the characteristic of the acoustic materials can be calculated. Impedance tube method is well suitable for the small sample size where as in case of the reverberation chamber larger number of samples is used. Standing wave method and transfer function method are two commonly used method of impedance tube. It is the direct method which involves calculation of the standing wave ratio (SWR). In this method microphone is moved along the length of the impedance tube by means of the carrier assembly. This most common and simple method is used to calculate the absorption coefficient $(\alpha)$ of the materials only. Here the sound of particular frequency is produced by means signal generator.

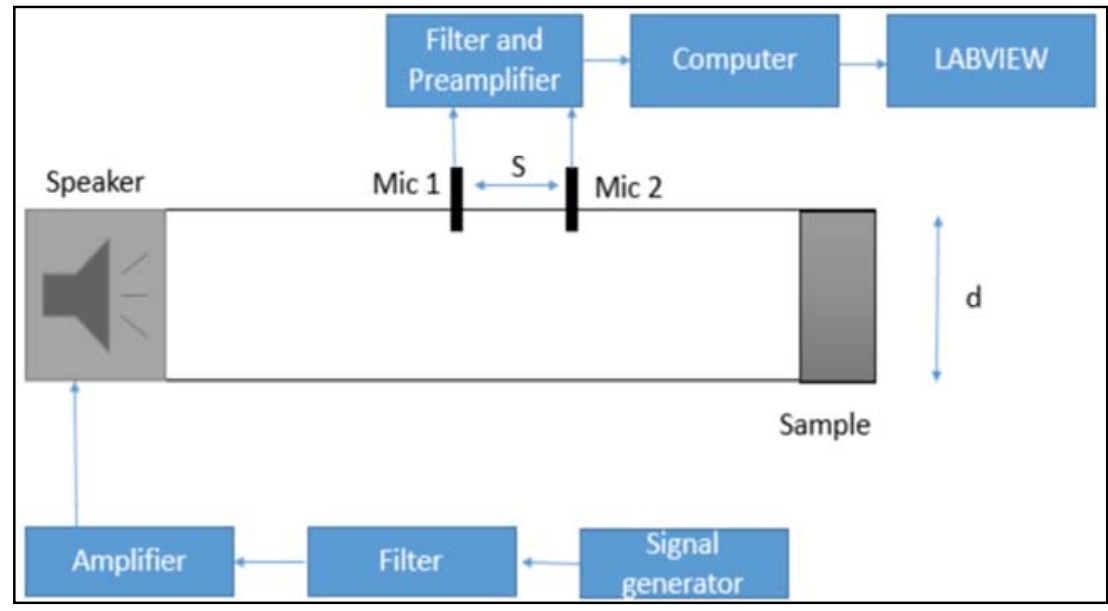

Figure 9. Schematic diagram of impedance tube test setup.

Figure 9 shows two microphone setup, loud speaker is kept at the one end of the impedance tube while the sample is kept at the other end of the impedance tube. two microphones are kept at the particular interval inside the impedance tube. This 
microphone converts the sound pressure inside the tube to respective voltage signal from that signal absorption coefficient can be calculated. Figure 10 shows Impedance tube test setup used for investigation of Sound absorption.

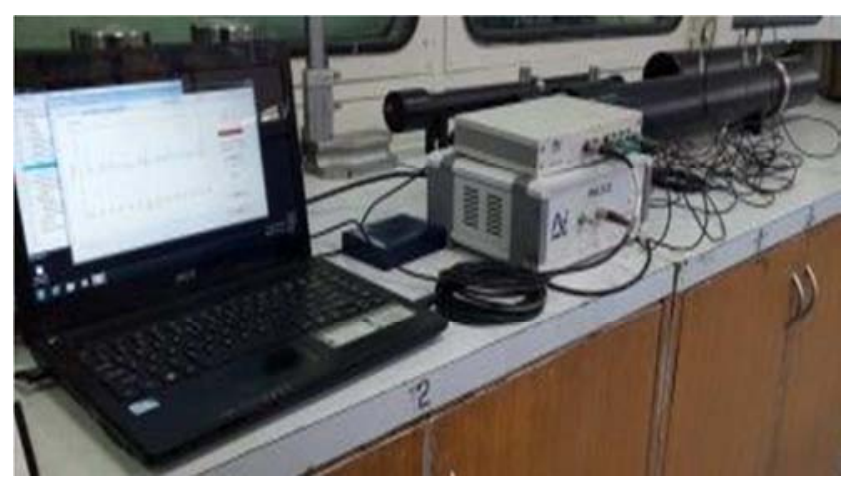

Figure 10. Impedance tube test setup.

Specifications of test setup:

Measurement Standard: ASTM E1050-98

Manufacturer: BSWA Technology Co., Ltd

Model Number: SW $422(63 \mathrm{~Hz} \sim 4500 \mathrm{~Hz})$

\section{Results and Discussion}

Results obtained through experimentation are shown in the form of graphs for test specimens with different material to binder ratios as shown below:

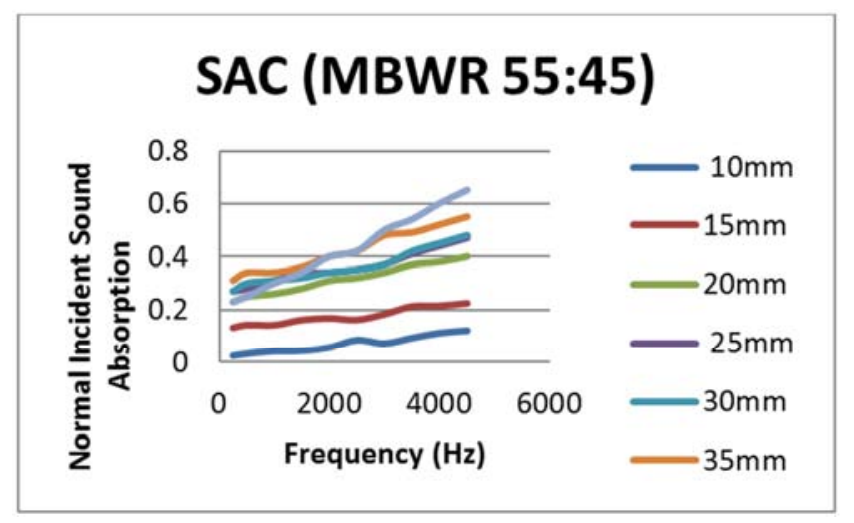

Figure 11. SAC for test specimen (MBWR 55.45).

From the Figure 11, it can be observed that sound absorption response curve for the test specimen with different thickness range is almost linear with respect to the frequency range of $250 \mathrm{~Hz}$ to $4500 \mathrm{~Hz}$. The curves for the $25 \mathrm{~mm}, 30$ $\mathrm{mm}, 35 \mathrm{~mm}$ and $45 \mathrm{~mm}$ thickness of test specimen intersect with each other at frequency range between $500 \mathrm{~Hz}$ to 1500 $\mathrm{Hz}$ due to the variying densities for respective specimens. The maximum sound absorption of 0.65 is obtained for the speciment having thickness $40 \mathrm{~mm}$ for the frequnency of 4500 $\mathrm{Hz}$. Similarly for the test speciment with thickness of $10 \mathrm{~mm}$ gives maximum sound absorption of 0.121 at the $4500 \mathrm{~Hz}$ of frequency.

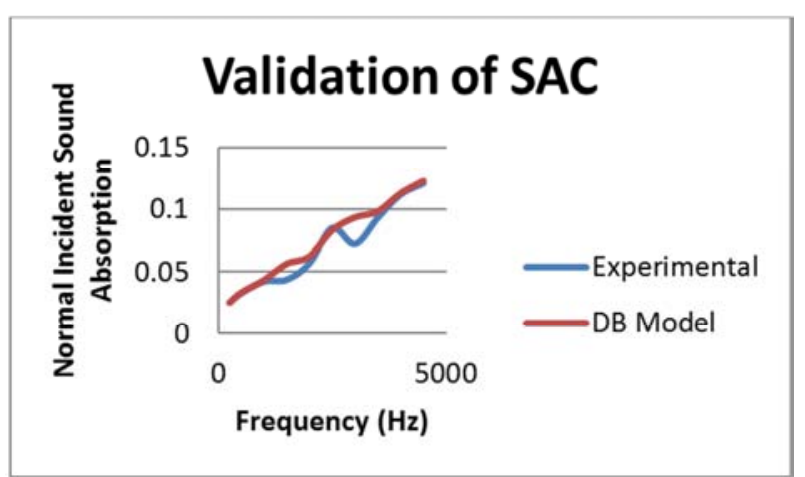

Figure 12. Comparison of results.

Validation of test results is done by comparision of the both experimental values with values obtianed by the DB Model for the $10 \mathrm{~mm}$ thickness test specimen with material to binder weight ratio 55:45 as shown in above the Figure 12.

Table 2. Comparison of SAC (10mm Specimen).

\begin{tabular}{lll}
\hline \multirow{2}{*}{ Frequency } & \multicolumn{2}{l}{ Sound Absorption Coefficient } \\
\cline { 2 - 3 } & Experimental & DB Model \\
\hline 250 & 0.025 & 0.0252 \\
500 & 0.0325 & 0.033 \\
1000 & 0.0421 & 0.0432 \\
1500 & 0.0435 & 0.0563 \\
2000 & 0.0566 & 0.0622 \\
2500 & 0.085 & 0.0832 \\
3000 & 0.072 & 0.0935 \\
3500 & 0.0932 & 0.0983 \\
4000 & 0.112 & 0.113 \\
4500 & 0.121 & 0.123 \\
Avg. Value & 0.06829 & 0.07309 \\
\hline
\end{tabular}

Above table 2 describes comparison of experimential and model values of Sound absorption coefficient for the $10 \mathrm{~mm}$ thickness specimen with material to binder weight ratio of $55: 45$. It can be observed that average experimental sound absorption value 0.06829 for frequency range of $250 \mathrm{~Hz}$ to $4500 \mathrm{~Hz}$. As the average value form the D B Model is 0.07309 for same frequnecy range. Percentage variation of the average experimental value from the average value obatined form the Delany \& Bazley model is about $6.56 \%$, Which is sufficent for verification of the experimental values with the values obtianed form mathematical model.

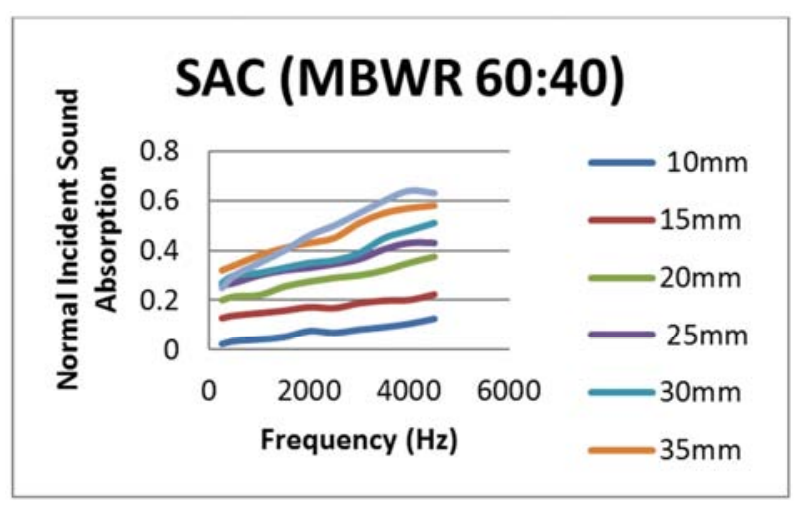

Figure 13. SAC for test specimen (MBWR 60.40). 
From Figure 13 similar response curves are generated for the test specimen with range of thickenss and material to binder weight ratio of 60:40. It can be observed that maximum sound absorption value for $40 \mathrm{~mm}$ thick specimen is 0.63 for frequency. SAC values for the frequency range between $250 \mathrm{~Hz}$ to $2500 \mathrm{~Hz}$ looks to be less than values compared with $35 \mathrm{~mm}$ thick specimen. This change occurs due to inherent porosity distribution throughout the specimen thickness.

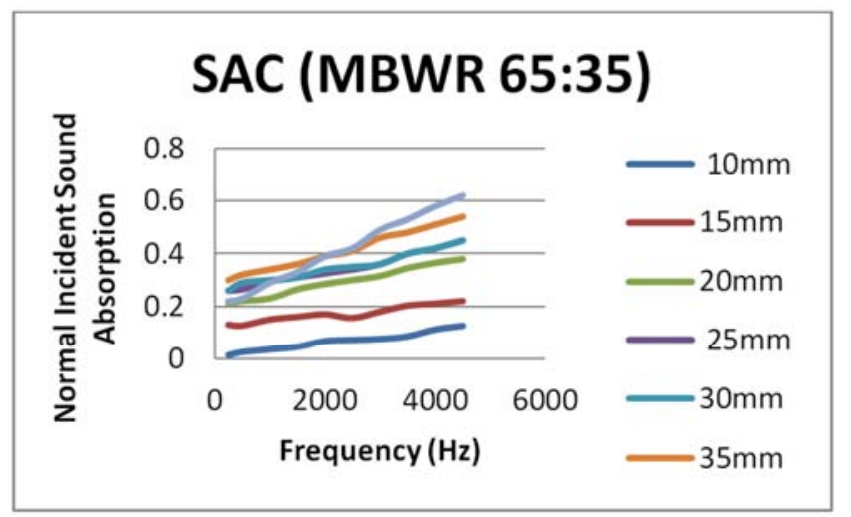

Figure 14. SAC for test specimen ( MBWR 65.35).

Figure 14 shows the sound absorption response curves for the different specimens with material to binder weight ratio of $65: 35$. It is observed that maximum sound absorption value obtianed for the $40 \mathrm{~mm}$ thick sample is about 0.625 and for sample with thickness $30 \mathrm{~mm}$ is 0.545 for frequency of $4500 \mathrm{~Hz}$.

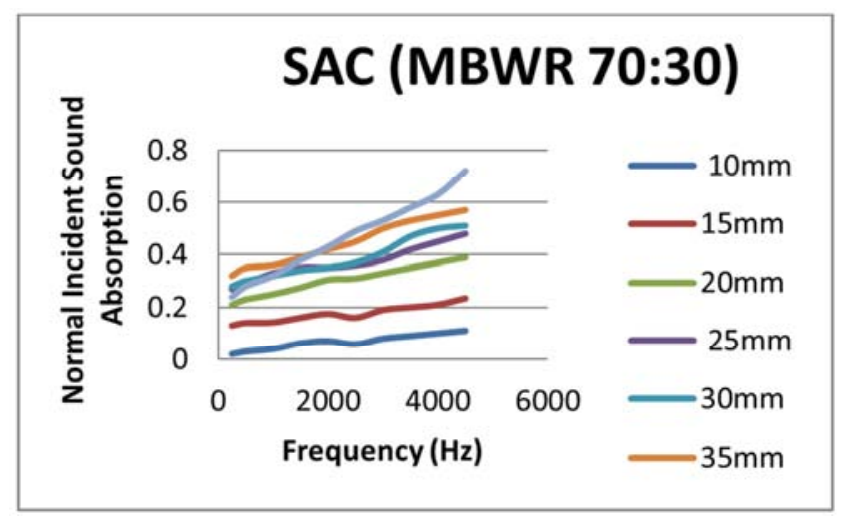

Figure 15. SAC for test specimen (MBWR 70.30).

Figure 15 shows the sound absorption response curves for the specimen with material to binder weight ratio of 70:30 for frequency range between $250 \mathrm{~Hz}$ to $4500 \mathrm{~Hz}$. It is observed that specimen with thickness $40 \mathrm{~mm}$ give maxium sound absorption of 0.72 at frequency of $4500 \mathrm{~Hz}$ and the curves of different thickness specimens varys as per the change in their densities and porosity in the specimen thickness for the frequency range between $250 \mathrm{~Hz}$ to $4500 \mathrm{~Hz}$.

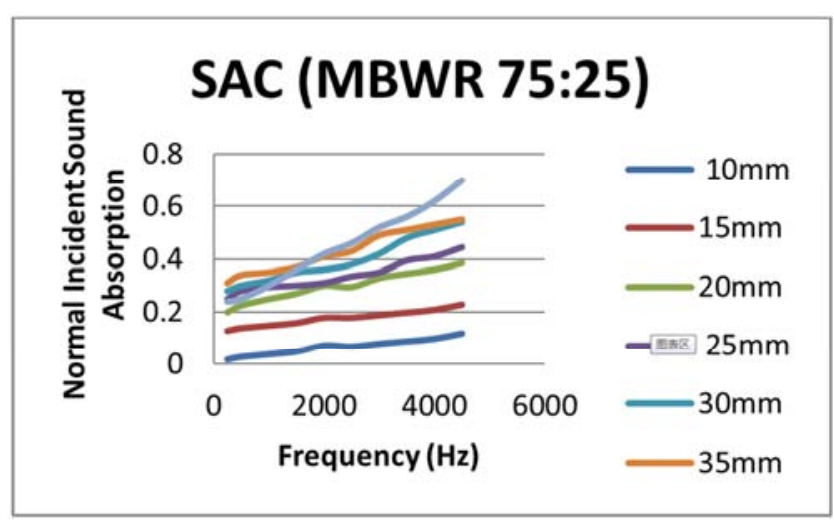

Figure 16. SAC for test specimen (MBWR 75.25).

Figure 16 shows the sound absorption response curves for the specimen with material to binder weight ratio of 75:25 for frequency range between $250 \mathrm{~Hz}$ to $4500 \mathrm{~Hz}$. It is observed that specimen with thickness $40 \mathrm{~mm}$ give maxium sound absorption of 0.70 at frequency of $4500 \mathrm{~Hz}$, but the values at lower frequencies is lower than values of specimen with $30 \mathrm{~mm}$ thickness. This occures due to curves of different thickness specimens varys as per the change in their densities and porosity in the specimen thickness for the frequency range between $250 \mathrm{~Hz}$ to $4500 \mathrm{~Hz}$.

\section{Conclusion}

Observation of sound absorption average (SAA) for test specimen with different material to binder weight ratios and thickness varies as result of uncertainties due to non-uniform varying inherent physical properties such as porosity and flow resistivity. Peanut shell test specimen with material to binder weight ratio 70:30 gives optimum average sound absorption for frequency range between $250 \mathrm{~Hz}$ to $4500 \mathrm{~Hz}$. Thus peanut shell could prove to be good alternative against existing synthetic sound absorbers.

\section{Funding Agency}

The authors acknowledge the funding granted by Board of College and University Development, Savitribai Phule Pune University, Pune.

\section{Conflict of Interest Statement}

All the authors do not have any possible conflicts of interest.

\section{Data Availability Statement}

The experimental results data recorded and used in this.

Research article are available from the corresponding author upon request. 


\section{References}

[1] Hasina Mamtaz, Mohammad Hosseini Fouladi, Mohd Zaki Nuawi, Satesh Narayana Namasivayam, Masomeh Ghassem, Mushtak Al-Atabi, Acoustic absorption of fibro-granular composite with cylindrical grains, Applied acoustics 126, 2017, pp 58-67.

[2] Zhengqing Liu, Jiaxing Zhan, Mohammad Fard, John Laurence Davy, Acoustic properties of multilayer sound absorbers with a 3D printed micro-perforated panel, Applied acoustics 121, 2017, pp 25-32.

[3] C. Arenas, C. Leiva, L. F. Vilches, J. A. González Ganso, Approaching a methodology for the development of a multilayer sound absorbing device recycling coal bottom ash, Applied acoustics 115, 2017, pp 81-87.

[4] Farhad Forouharmajd, Zahra Mohammadi, Assessment of normal incidence absorption performance of sound absorbing materials, International Journal of Environmental Health Engineering 1, 2017, 1-9.

[5] Khai Hee Or, Azma Putra, Mohd Zulkefli Selamat, Oil palm empty fruit bunch fibres as sustainable acoustic absorber, Applied acoustics 119, 2017, pp 09-16.

[6] B. Botterman, G. C. H. Doudart de la Grée, M. C. J. Hornikx, Q. L. Yu, H. J. H. Brouwers, Modelling and optimization of the sound absorption of wood-wool cement boards, Applied acoustics 129, 2017, pp 144-154.

[7] Mathan Sambu, Musli Nizamyahya, Hanif Abdul Latif, Mohamed Nasrul Mohamed Hatta and Mohd Imran Bin Ghazali, Acoustic Performance and physical properties of nonwoven fiber; Aregna Pinnata (Ijuk) And Natural Rubber composite, ARPN Journal of Engineering and Applied Sciences 11, 2016, pp 13292-13299.

[8] Hasina Mamtaz, Mohammad Hosseini Fouladi, Mushtak Al-Atabi, and Satesh Narayana Namasivayam, Acoustic Absorption of Natural Fiber Composites, Hindawi Publishing Corporation Journal of Engineering Volume 2016, pp 1-11.
[9] Ancuța-Elena Tiuca, Horaţiu Vermeşana, Timea Gabora, Ovidiu Vasileb, Improved sound absorption properties of polyurethane foam mixed with textile waste, Sustainable Solutions for Energy and Environment, EENVIRO-YRC 2015, pp 18-20.

[10] Cinzia Burattia, Elisa Bellonia, Elisa Lascarob, Giovanna Anna Lopez, Paola Ricciardic, Sustainable panels with recycled materials for building applications: environmental and acoustic characterization, 71st Conference of the Italian Thermal Machines Engineering Association, ATI2016, pp 14-16.

[11] Daniela Bosnia, Lorenzo Savioa, Francesca Thiebata, Alessia Patruccob, Stefano Fantuccic, Gabriele Piccablottoa, Donatella Marinoa, Sheep Wool for Sustainable Architecture, Energy Procedia 78, 2015, pp 315-320.

[12] M. T. Fadzlita, K. B. Yeo, W. H. Choong, M. Melvin, Absorption coefficient of acoustic coir fiber panel and effects of varying percentages of perforated plates, journal of applied sciences 14, 2014, pp 3106-3109.

[13] K. Elwaleed, N. Nikabdullah, M. J. M. Nor, M. F. M. Tahir, M. Z. Nuawi and Y. A. Abakr, Experimental Study on the Effect of Compression on the Sound Absorption of Date Palm Fibers, World Applied Sciences Journal 31, 2014, pp 40-44.

[14] Tu-Cheng Hung, Jong-Shin Huang, Yi-Wen Wang, Kuei-Yi Lin, Inorganic Polymeric Foam as a sound absorbing and insulating material, Construction and Building Materials 50, pp2014, pp 328-334.

[15] Hai-fan Xianga, Dong Wanga, Hui-chao Liua, Ning Zhaoa and Jian Xua, Investigation on sound absorption properties of kapok fibers, Chinese Journal of Polymer Science 31, 2013, pp 521-529.

[16] Lamyaa Abd ALRahman, Raja Ishak Raja and Roslan Abdul Rahman, Experimental study on Natural Fibers for Green Acoustic Absorbing Materials, American Journal of Applied Sciences 10, 2013, pp 1307-1314.

[17] Sezgin Ersoy, Haluk Ku"cu"k, Investigation of industrial tea leaf fibre waste material for its sound absorption properties, Applied Acoustics 70, 2009, pp 215-220. 